The following paper posted here is not the official IEEE published version. The final published version of this paper can be found in the Proceedings of IECON 2007 (33rd : 2007 : Taipei, Taiwan):pp.1268-1273

Copyright (c) 2007 IEEE.

Personal use of this material is permitted. However, permission to reprint/republish this material for advertising or promotional purposes or for creating new collective works for resale or redistribution to servers or lists, or to reuse any copyrighted component of this work in other works must be obtained from the IEEE. 


\section{Analysis of a Segmented Brushless PM Machine Utilising Soft Magnetic Composites}

\author{
G.S. Liew, E.C.Y. Tsang, N. Ertugrul and W.L. Soong \\ School of Electrical \& Electronic Engineering \\ University of Adelaide, Adelaide, Australia \\ Email : gliew@eleceng.adelaide.edu.au
}

\author{
D. Atkinson and D.B. Gehlert \\ Intelligent Electric Motor Solutions Pty. Ltd. \\ Adelaide, Australia \\ Email : davidg@diga.com.au
}

\begin{abstract}
Soft magnetic composites (SMC) is a magnetic material which offers the potential for innovative machine geometries and lower cost manufacturing. This paper examines the finite-element analysis and performance prediction of a segmented brushless permanent magnet machine based on SMC. Experimental results including the back-EMF waveform, iron loss and performance characteristics are used to validate the simulation results.
\end{abstract}

\section{INTRODUCTION}

\section{A. Background}

Soft magnetic composites (SMC), also known as powdered iron, are emerging in electrical machine design specifically for small and medium size machines. SMC consists of fine iron powder coated with a small amount of a binder which also serves to insulate the particles from one another. SMC can be moulded to theoretically any shape using a similar process to injection moulding of plastics. It is thus possible to use SMC to produce machine designs which require three-dimensional (3D) flux paths and geometries.

SMC offers a simplified manufacturing method and the potential for constructing complex 3D machine geometries at much lower cost. Furthermore, new machine design topologies with innovative shapes, reduced size and weight, and better winding utilisation are possible by using SMC's 3D flux capability [1-2].

Iron losses in magnetic materials consist of eddy-current losses and hysteresis losses. The insulation between the iron particles gives SMC a high electrical resistivity and hence low eddy-current loss. The moulding process however leaves high residual mechanical stress in the iron particles and hence produces high hysteresis loss. Although SMC has higher iron loss compared to conventional silicon-iron (SI) at low frequencies where the hysteresis loss is dominant, the iron loss of SMC becomes comparable to SI at higher frequencies where the eddy-current loss is dominant. This was experimentally demonstrated in [3].

The insulation between the iron particles in SMC also gives it a relatively low magnetic permeability $\left(\mu_{R}<1000\right)$ which makes it better suited to permanent magnet (PM) machines than reluctance or induction machines.

\section{B. Literature Review}

The traditional laminated motor construction is inherently limited to 2D magnetic structures with 2D flux paths to avoid excessive eddy-current losses caused by flux passing perpendicularly through laminations. A key benefit of SMC is its ability to produce machines with $3 \mathrm{D}$ magnetic geometries and 3D flux paths. In the literature, 3D SMC core structures have been examined for:

- transverse-flux machines : these are well suited to high torque, low speed, direct-drive applications [4],

- axial-flux machines : high torque density applications such as small wind turbines [5-6], and

- tubular linear machines : for linear motion applications such as reciprocating compressors [7].

SMC has also been applied to radial flux machines. In [3] a radial flux machine with a laminated yoke and SMC teeth was described. This machine still has a largely 2D magnetic structure.

The 3D SMC flux capability was applied more effectively in $[8,11]$ which used a segmented tooth construction for a radial flux machine. In this design the axial ends of each tooth were rounded to allow easier winding and better thermal contact with the concentrated winding. Each stator tooth was wound before being assembled allowing high slot fill factors. The stator core and tooth tips were axially longer than the tooth body to reduce the stator back iron thickness and allow the use of longer magnets. In [11] the radial SMC machine was compared to a conventional laminated machine. The use of SMC was found to significantly increase the torque capability while substantially reducing the amount of copper used in the design.

This paper investigates the finite-element analysis of the performance of an SMC-based radial flux PM concept demonstrator machine which uses a similar stator construction to that described in [8]. A detailed comparison between the measured and simulated results is provided.

\section{PROTOTYPE SMC PM MOTOR}

Fig. 1 shows the prototype three-phase, eight-pole SMC PM machine topology. The stator coil has been removed from the left-most stator tooth to show the tooth geometry. The axial length of the tooth body was designed to be shorter than that of the tooth tip and stator back-iron in order to improve the stator winding utilisation. The stator tooth design is similar to [8] with the main difference that the teeth were moulded in a single piece.

The twelve stator teeth were constructed by moulding SMC in a precision, custom-built die. This approach gives much better dimensional tolerances and surface finish than can be achieved by machining. The teeth were wound with a concentrated stator winding and assembled together in a specially designed housing. The stator coils in each phase were connected in series to form a star-connected winding.

The eight-pole rotor was constructed using arc-shaped magnets on a solid mild steel back-iron (see Fig. 1). The 
magnets were segmented in an axial direction into five sections and these were skewed in a step-wise fashion to reduce cogging torque. The total rotor skew was $56^{\circ}$ electrical. Table 1 summarizes some of the key parameters and dimensions of the prototype machine.

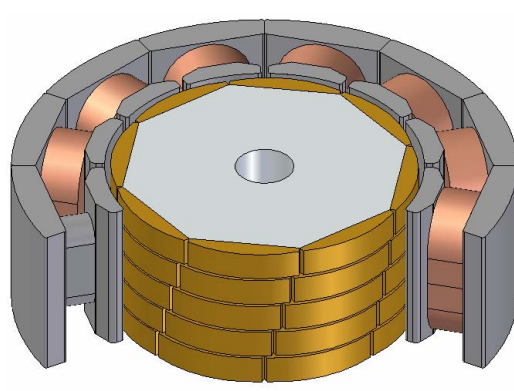

a

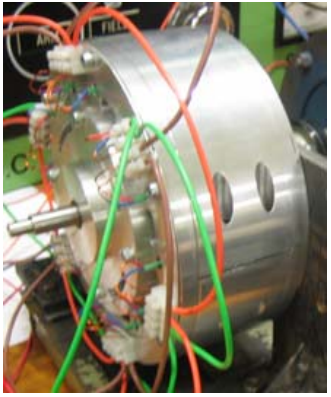

b
Fig. 1 a) The SMC based PM machine stator and rotor geometry showing the segmented teeth with concentrated windings and the rotor step skewing. b) The prototype machine on the dynamometer.

The rotor position was obtained using three Hall-Effect sensors, which are excited by a separate PM disk attached to the end of the rotor. The test setup also included a dc machine, which was used to drive and load the PM machine during the parameter and performance measurements.

TABLE I

Key PARAMETERS AND DimENSIONS OF THE PROTOTYPE SMC MACHINE

\begin{tabular}{|l|c|l|c|}
\hline Parameters & & Dimensions & mm \\
\hline Stator Core Material & Somaloy 550 & Stator OD & 190 \\
\hline Magnet Material & $\mathrm{NdFeB}, B_{r} 1.05 \mathrm{~T}$ & Stator ID & 120 \\
\hline Rated dc Link Volt. & $340 \mathrm{~V}$ & Stack Length & 60 \\
\hline Rated Phase Current & $4 \mathrm{~A}$ & Air Gap Length & 2 \\
\hline Rated Phase Voltage & $114.6 \mathrm{~V}$ & Magnet Length & 7.15 \\
\hline Rated Torque & $17.5 \mathrm{Nm}$ & & \\
\hline Rated Speed & $750 \mathrm{rpm}$ & & \\
\hline Rated Current Density & $5 \mathrm{~A} / \mathrm{mm}^{2}$ & & \\
\hline Winding Packing Factor & $60 \%$ & & \\
\hline Phase Resistance & $2.0 \Omega$ & & \\
\hline
\end{tabular}

\section{Finite-Element Modeling}

Finite-element analysis (FEA) is a numerical method that can accurately analyze complex electromagnetic fields using Maxwell equations. The 2D/3D FEA package JMAG Studio [9-10] was utilized in this study to analyze, to simulate and to predict the characteristics of the prototype motor.

A 2D finite-element model was used despite the rotor step-wise skewing and the shorter axial length of the stator tooth body, as a 3D FEA model would be quite complex. Fig. 2 shows the actual 3D SMC tooth face, tooth body and coil. It also shows the two 2D FEA models which were used to represent the $3 \mathrm{D}$ structure, both which use a stack length equal to the original tooth and yoke length. The "original" FEA model uses the same width for the tooth body but extends this to over the full length of the machine. However this over-estimates the tooth body cross-sectional area. The "modified" FEA model uses a narrower tooth body width to give it the same tooth body cross-sectional area as the actual machine.

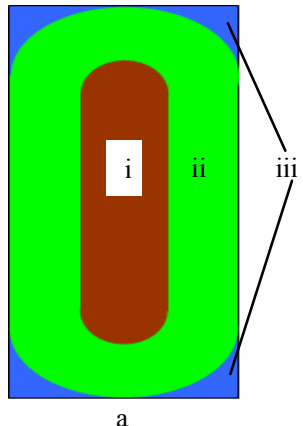

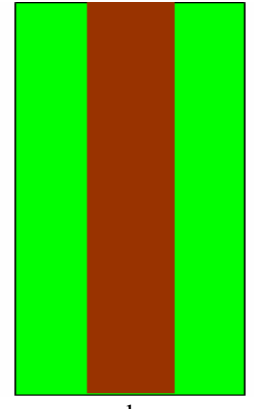

$\mathrm{b}$

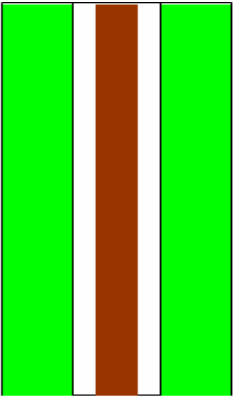

$\mathrm{c}$
Fig. 2 a) Real SMC structure. i: tooth body, ii: coil, iii: tooth face b) original FEA model c) modified FEA model.

The simulation results are from a time-stepping, coupled-circuit 2D finite element simulation. Considering the $90^{\circ}$ periodicity of the motor, quarter machine models were used to reduce the analysis computation time (see Fig. 3). The mesh of the models consists of 1,807 nodes and 2,774 elements. The BH-curves and iron loss characteristics available in the JMAG material database for the SMC material grade was used. The total execution time was approximately 8 minutes for 180 steps.
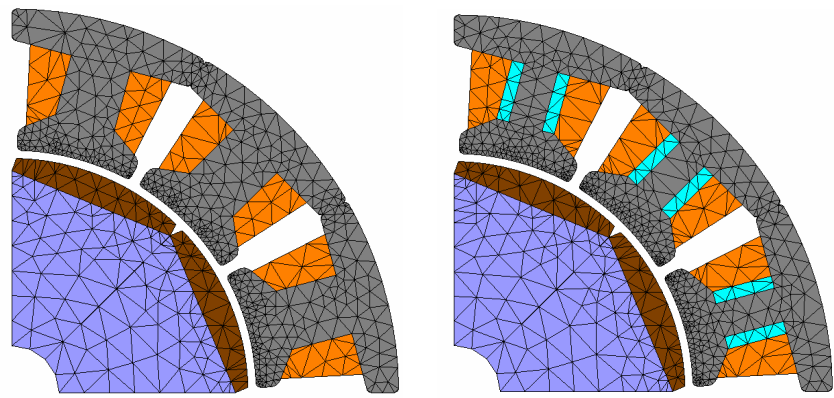

Fig. 3. The two FEA models : Original model (left) and modified model which takes into account the shorter axial length of the tooth body (right).

The effect of the rotor stepwise skewing was compensated for in the back-emf, flux and cogging torque calculations by time-shifting the FEA results by the electrical skew angle and taking the average of five time-shifted results. This is only a first-order approximation to step-wise skewing as it neglects the effect of axial fluxes.

Fig. 4 shows some finite-element analysis results from the modified model under open-circuit conditions: flux distribution (left), and the iron loss density plot at $1000 \mathrm{rpm}$ (right).
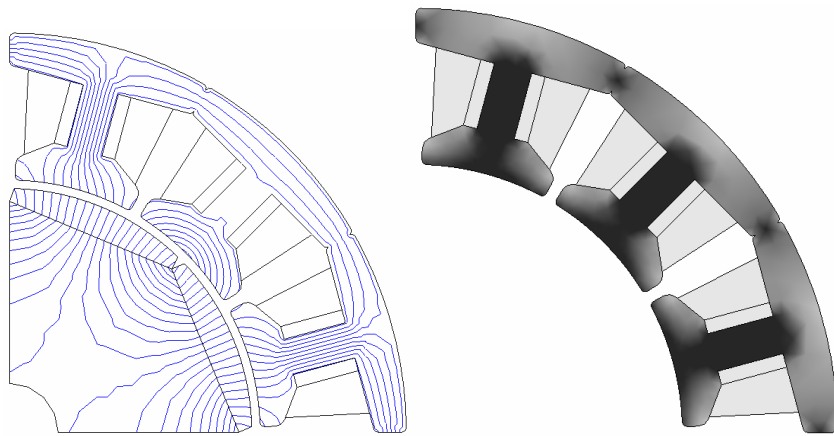

Fig. 4. 2D FEA simulation results from the modified machine model. Open-circuit flux plot (left) and open-circuit iron loss density plot (right) at $1000 \mathrm{rpm}$. 


\section{MACHINE PARAMETER CHARACTERISTICS}

This section shows a comparison between the calculated and measured machine parameters. A similar experimental procedure to that described in [6] was performed.

\section{A. Back EMF Waveforms}

Fig. 5 shows the measured phase back EMF waveform and the three simulated FEA waveforms. The simulated waveform from the original FEA model in Fig. 2 is labelled "JMAG Original". As it does not properly model the shorter tooth body axial length and hence saturation, it over-estimates the back-emf amplitude but has a reasonable correspondence with the waveform shape. The simulated waveform from the modified FEA model from Fig. 3 (labelled "JMAG"), shows a much better match with the measured result indicating that stator tooth saturation is significant in this machine. It is interesting to see that when the skewing compensation described earlier is introduced to the modified FEA model results "JMAG Skewed", the prediction of the waveform shape became considerably worse. The reason for this is still under investigation.

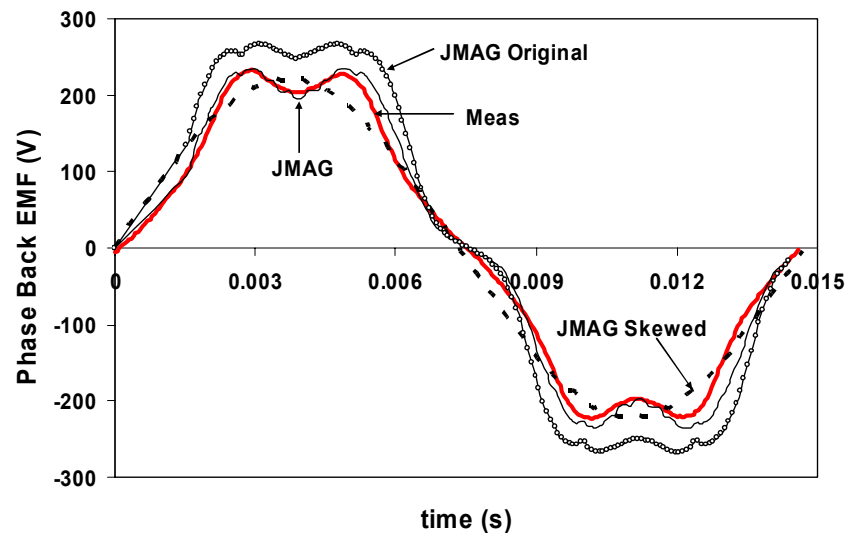

Fig. 5. Phase back-EMF waveforms at $1000 \mathrm{rpm}$ : measured (Meas), simulated using original model (JMAG Original, solid line with circle markers), simulated with modified model (JMAG, solid line) and simulated with modified model with skew compensation (JMAG skew, dashed line).

\section{B. Tooth and Yoke Flux Density Waveforms}

Figs. 6 and 7 show the measured and simulated stator tooth and yoke flux density waveforms. The flux measurements were conducted using search coils. The flux waveform was obtained by numerically integrating the induced voltage and then scaled in terms of flux density.

As with the back-emf case, the original model substantially over predicts both the stator tooth and yoke flux densities. The modified model gives a much better prediction of the flux density amplitude and waveform shape. The skew compensation method appears to give a slightly worse prediction.

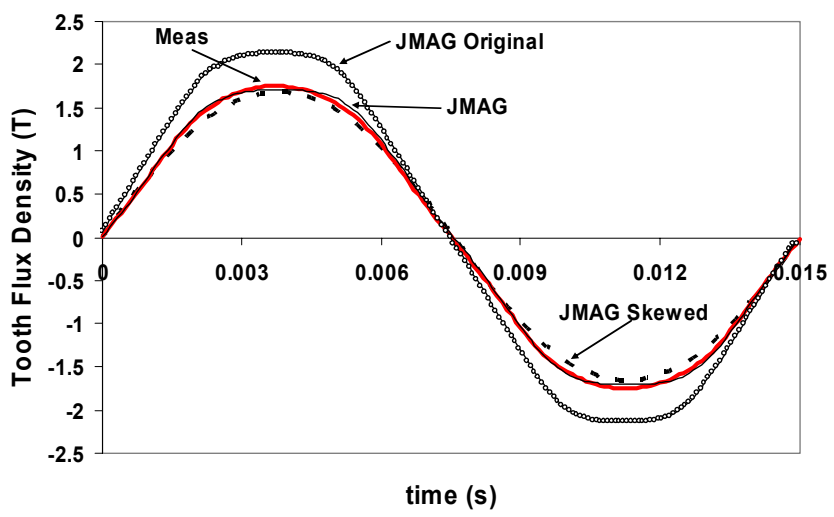

Fig. 6. Stator tooth body flux density waveforms : measured (Meas), original model (JMAG Original), modified model (JMAG), and modified model with skew compensation (JMAG skew). The original model results have been scaled to take into account the actual tooth area.

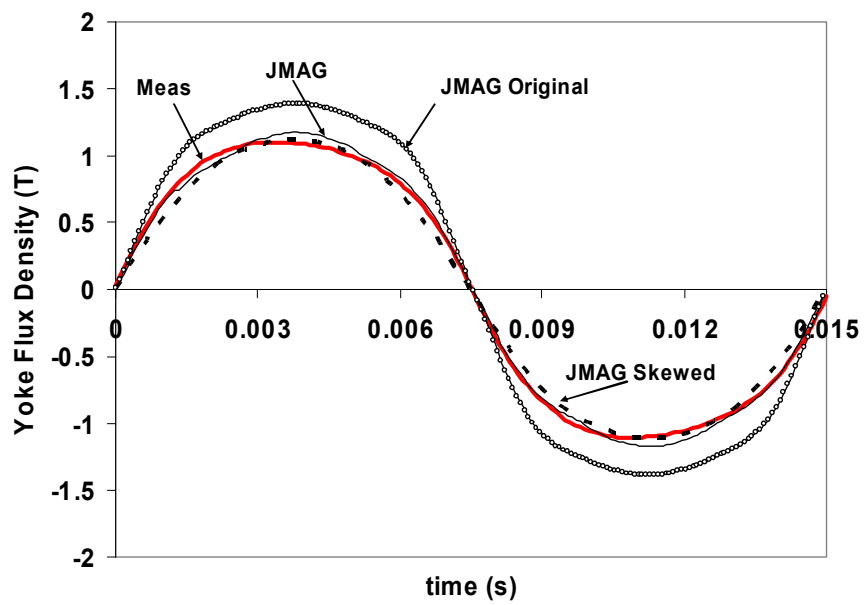

Fig. 7. Stator yoke flux density waveforms : measured (Meas), original model (JMAG Original), modified model (JMAG), and modified model with skew compensation (JMAG skew).

\section{Inductance}

Due to the surface PM machine topology, the machine shows little saliency between the $d$ - and $q$-axes.

The inductance of the test motor at standstill was measured using a single-phase $50 \mathrm{~Hz}$ sinusoidal AC excitation applied between two of the motor terminals and the third terminal. From the measured stator voltage and current and with knowledge of the stator resistance, the reactance and hence inductance was determined.

In order to simulate the inductance of the motor in FEA, the built in PM motor inductance tool was used. The inductance versus current characteristic was calculated using both the SMC magnetic characteristics and also with iron with a constant permeability of $\mu_{\mathrm{R}}=5,000$.

Fig. 8 shows the measured and simulated inductances for the machine with and without the rotor. With the rotor, the measured inductance is about $40 \mathrm{mH}$ which matches the SMC FE results well. It should be noted that use of the modified FEA model in Fig. 2 has greater slot leakage than the real machine, however the real machine also has end-winding leakage which would not normally be modeled in a 2D FEA model. Given the 2D FEA results show a good correspondence with the measurements, these two effects are likely to be comparable.

When the rotor is removed the measured inductance 
increases to about $70 \mathrm{mH}$. The SMC FE results also show an increase inductance but not as much as was measured. This increase in inductance with the removal of the rotor is thought to be due to heavy stator tooth saturation by the magnet flux (see Fig. 6). Fig. 8 also shows FE results with the ideal iron (assuming constant $\mu_{\mathrm{R}}=5,000$ ) where the inductance with the rotor increases to about $80 \mathrm{mH}$ and the inductance when the rotor is removed drops to about $70 \mathrm{mH}$ which is comparable to the measured value.

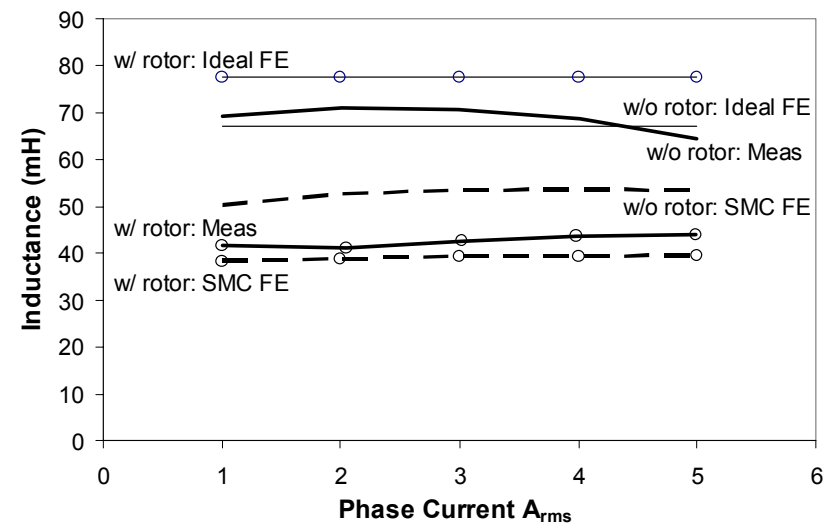

Fig. 8. SMC machine inductance : with and without rotor for three cases : measured, calculated from FE using SMC characteristics and calculated from FE using ideal non-saturating iron $\left(\mu_{\mathrm{R}}=5000\right)$

\section{Iron Loss}

In the FEA, the open-circuit iron loss was calculated using the magnetic field variation in each element in the model as the rotor rotates. The hysteresis and eddy-current iron loss are calculated separately based on the SMC iron loss characteristics available in JMAG, and then summed together to give the total iron loss. The available SMC iron loss data only covered the range from 50 to $400 \mathrm{~Hz}$ and so the iron loss calculation was extrapolated for frequencies out of this range.

Fig. 9 shows the measured and simulated total open-circuit iron loss versus speed characteristic. In addition, the simulated hysteresis and eddy current losses are also shown. The modified FE model was used for the calculations. The open-circuit iron loss was measured using the dc motor as a torque transducer and includes the windage and bearing losses in the SMC machine.

It can be seen that hysteresis losses are dominant in this SMC machine over the speed range considered, but that as the speed is increased further that eddy-current losses will become more important. The measured losses show a good correspondence with the simulated losses at lower speeds, but are significantly higher at higher speeds. This is likely to be due to the inclusion of friction and windage losses in the measurements which become more significant at higher speeds.

The iron loss density plot of the stator was given in Fig. 4 (right). This gives a better view of where the iron losses are occurring in the stator. The plot shows that the majority of the stator iron losses are concentrated at the tooth body and tooth tips.

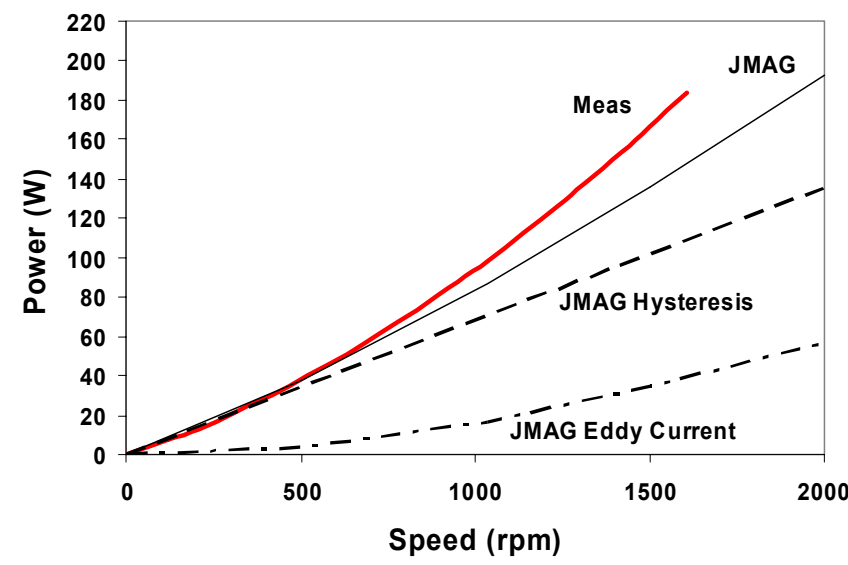

Fig. 9. Open-circuit iron loss as a function of speed. Measured (solid, thick) curve. Simulated with modified FE model : hysteresis (dashed), eddy-current loss (dash-dot) and total loss (solid).

\section{E. Cogging Torque}

The calculated cogging torque using the original model and the modified model with and without skew compensation is shown in Fig. 10. They are respectively 5\%, 3\% and $12 \%$ of the rated torque of $17.5 \mathrm{Nm}$. Due to hardware limitations these results were not validated experimentally. It is interesting that the calculated cogging torque amplitude for the original model is about half that for the modified model, and thus that saturation effects in the stator teeth result in a doubling of the peak cogging torque. It can be observed that the magnitude of the calculated skewed cogging torque is very much smaller compared to the unskewed result with an approximately $70 \%$ reduction.

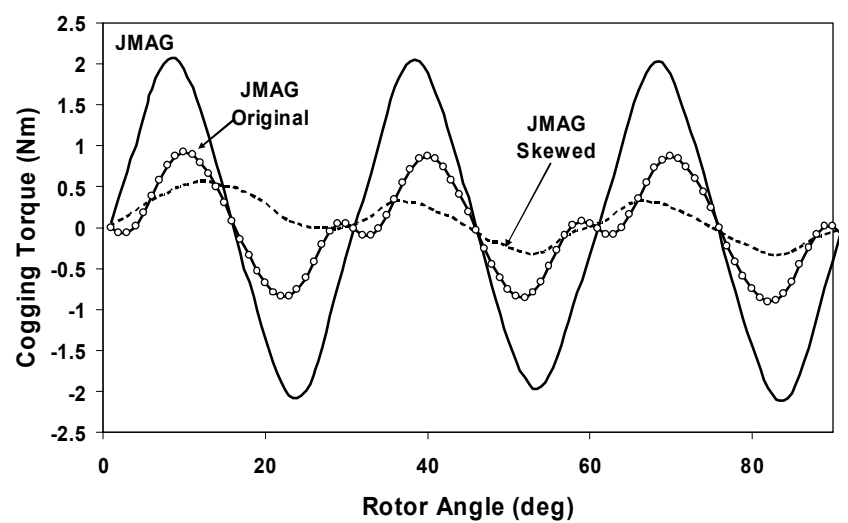

Fig. 10. Calculated cogging torque : original model (JMAG Original), modified model (JMAG) and modified model with skew compensation (JMAG skew).

\section{PERFormance INVESTIGATION}

The SMC machine was designed for an inverter with a $340 \mathrm{Vdc}$ link voltage, however during the testing only an inverter with a $48 \mathrm{Vdc}$ link voltage was available and thus the maximum speed which could be tested was limited. The inverter provided a six-step rectangular voltage output and used three Hall-effect position sensors.

In the FEA, the coupled-circuit model includes a voltage source, six-switch inverter and the star-connected motor windings. The switching instants were synchronised with the back-emf waveforms.

Figs. 11 and 12 show the measured and simulated phase 
voltage and phase currents at $104 \mathrm{rpm}$ and $6 \mathrm{Nm}$. As shown in the figures, the simulation results are in reasonable agreement with the measured waveforms. The discrepancies in the waveforms could be due to the error in the back-emf and inductance parameters.

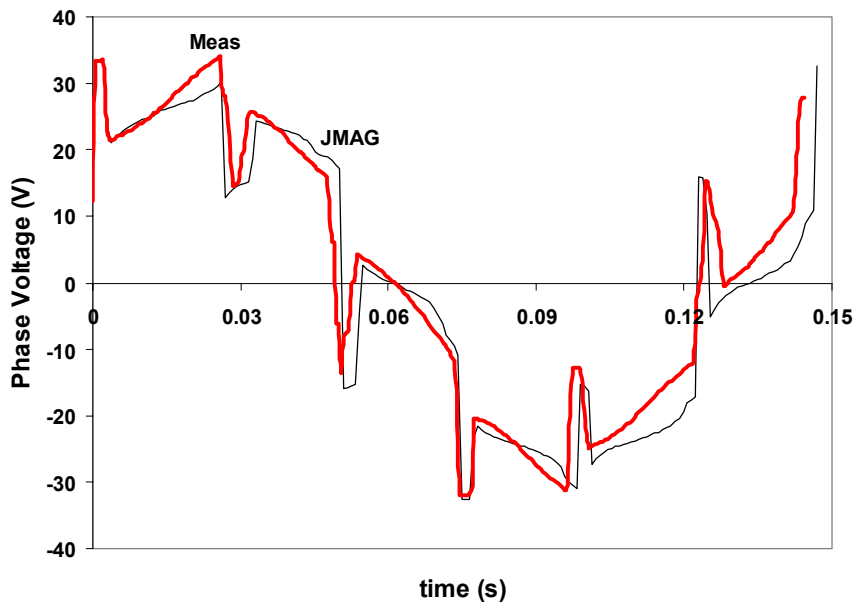

Fig. 11. Phase voltage waveforms at $104 \mathrm{rpm}:$ measured (Meas) and simulated (JMAG)

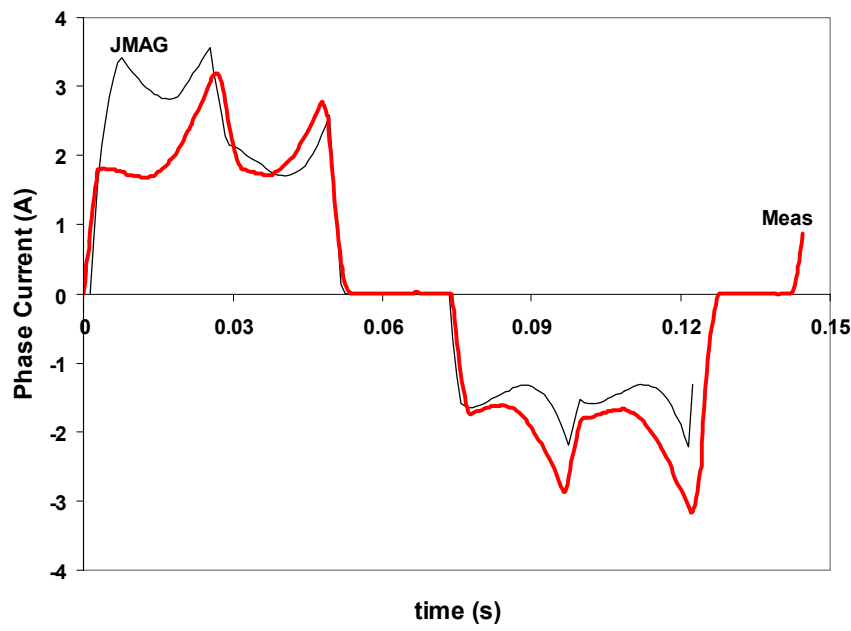

Fig. 12. Phase current waveforms at $104 \mathrm{rpm}$ : measured (Meas), simulated (JMAG).

\section{A. Load Performance and Efficiency}

Fig. 13 shows the measured and simulated speed versus output torque. These have the expected linear drop in speed with increasing torque. As can be seen from Fig. 13, the simulated and measured curves are comparable.

Fig. 14 shows the measured and simulated efficiency of the motor under test corresponding to the operating points shown in Fig. 13. The simulated efficiency (JMAG) was calculated based on the current and torque predictions of the circuit-coupled time-stepping FEA at each test speed. The copper loss was calculated using the measured winding resistance, and the iron loss was calculated from the calculated no-load iron loss at that speed (see Fig. 9). The JMAG results show a good correspondence with the measured results.

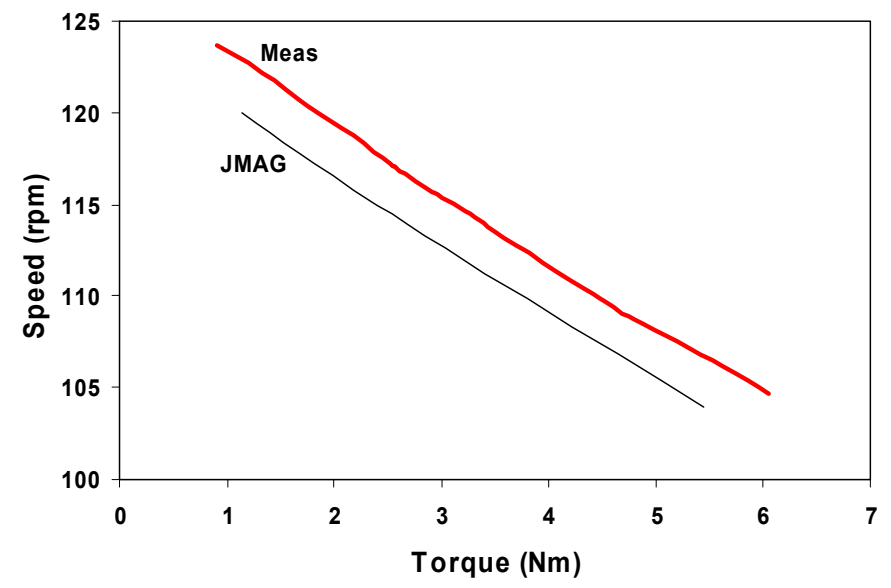

Fig. 13. Measured and simulated speed versus output torque with the $48 \mathrm{~V} \mathrm{dc}$ link inverter.

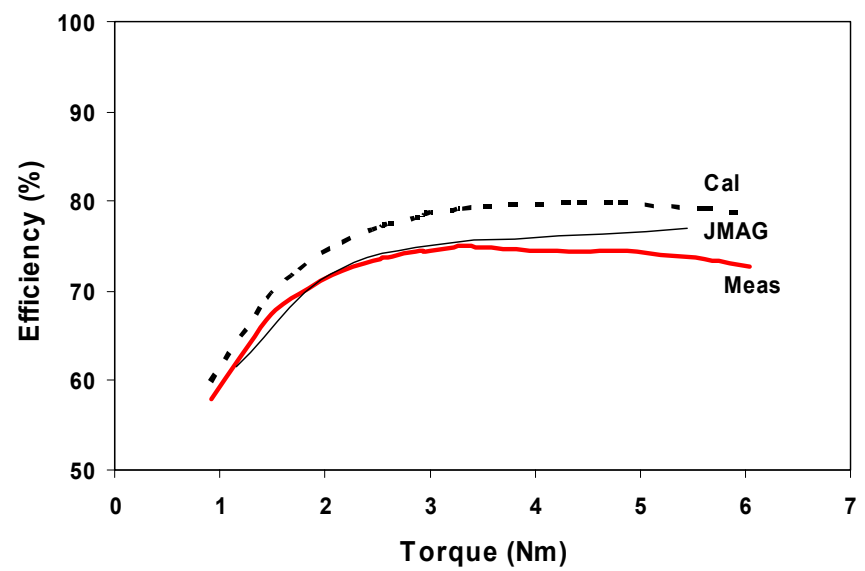

Fig. 14. Efficiency versus output torque corresponding to the operating points shown in Fig. 13. Measured (Meas), simulated using JMAG (JMAG) and calculated based on the measured resistance, back-emf and iron loss

$$
\text { (Cal). }
$$

The motor reached a maximum measured efficiency of $75 \%$ at a load torque of about 3 to $4 \mathrm{Nm}$ and this decreased at higher loads. The drop in efficiency at higher loads is due to the increase of the copper loss. This is shown in Fig. 15 which shows a loss breakdown corresponding to the operating condition in Fig. 13. The copper loss was determined from the measured load current and the iron loss was determined from the measured no-load losses.

\section{B. Efficiency Prediction}

The efficiency contour plot shown in Fig. 16 was calculated based on the measured motor resistance, back-emf and open-circuit iron loss characteristic. It was assumed that the inverter currents were sinusoidal and in phase with the back-emf. The copper loss dominates at low speed and high torque, while the iron loss dominates at high speed and low torque.

Fig. 16 also shows the measured torque versus speed points corresponding to Fig. 13. The calculated efficiencies corresponding to these points were shown in Fig. 14. Fig. 14 shows that the calculated efficiency curve matches the shape of the measured curve reasonably well but over predicts the efficiency by a couple percent at light loads and up to six percent at higher loads. This is likely to be due to the assumption of a sinusoidal phase current waveform.

From Fig. 16 the peak calculated efficiency for the test 
machine is $88 \%$. The motor can generally maintain efficiencies of greater than $80 \%$ for torques $>4 \mathrm{Nm}$ and speeds $>150 \mathrm{rpm}$.

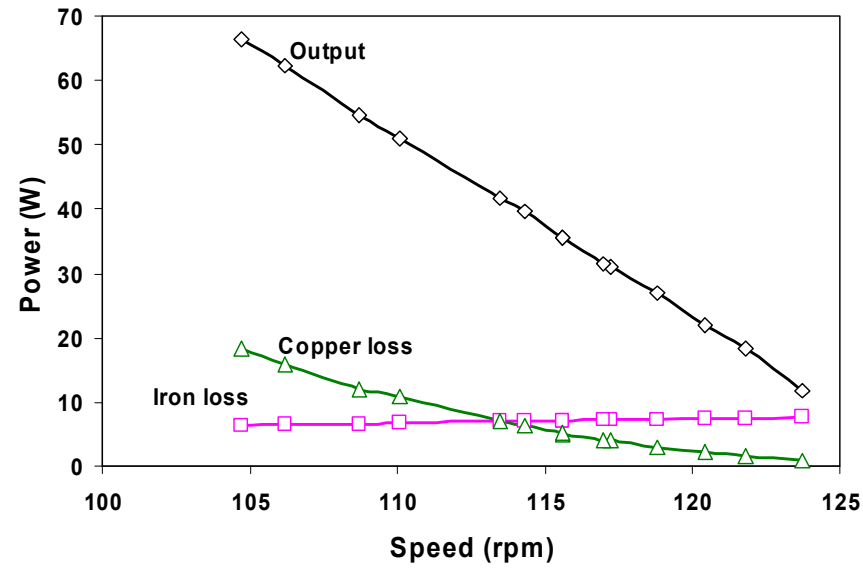

Fig. 15. Measured copper and iron loss breakdown versus speed corresponding to the results shown in Fig. 15. The measured output power is also shown.

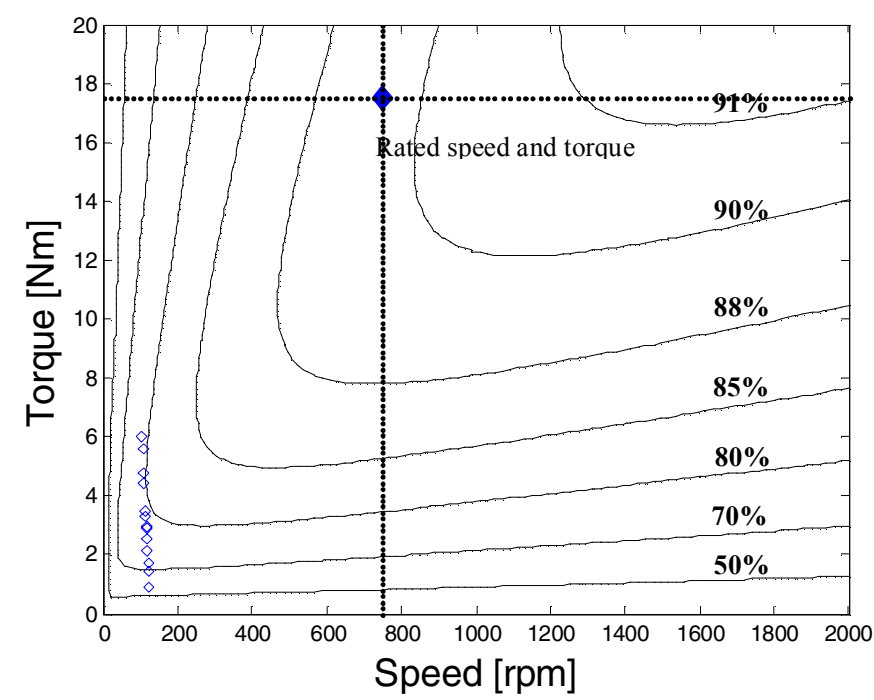

Fig. 16. Calculated efficiency contours based on the measured resistance, back-emf and iron loss. The measured torque versus speed points (circles) corresponding to Fig. 14 are also shown.

\section{CONCLUSIONS}

This paper has examined the parameter and performance prediction of a soft magnetic composite (SMC) brushless PM machine using 2D finite-element analysis (FEA). Detailed comparisons were presented between measured and simulated results to examine the validity of the analysis approach. It was shown that 2D FEA can give reasonably accurate predictions of the back-emf magnitude, tooth and yoke flux waveforms, inductance and iron loss in this machine.

The test results showed the feasibility and potential of SMC for achieving reasonable efficiency in low-cost, high-volume machine applications.

In future work it is planned to design and construct a conventional laminated stator which has the same stator outside diameter and uses the same rotor as the SMC machine which will allow a detailed performance comparison.

\section{ACKNOWLEDGMENT}

This paper is dedicated to the co-author Don Atkinson who performed the initial design of the machine, but sadly passed away during the preparation of the paper.

The authors would like to thank the Australian Research Council (ARC Linkage Project: LP0455574) for supporting this project and the staff of the School of Electrical and Electronic Engineering's mechanical workshop for their help with the experimental testing.

\section{REFERENCES}

[1] L. Hultman and A.G. Jack, "Soft Magnetic Composites - Motor Design Issues and Applications", Powder Metallurgy and Particulate Materials (PM2TEC) 2004, Chicago, USA June 2004.

[2] M. Persson, G. Nord, L. Pennander, G. Atkinson and A.G. Jack, "Development of Somaloy Components for a BLDC motor in a Scroll Compressor Application", Powder Metallurgy (PM) World Congress \& Exhibition 2006, Busan, Korea September 2006.

[3] Y. Enomotor, et al., "Evaluation of Experimental Permanent-Magnet Brushlesss Motor Utilising New Magnetic Material for Stator Core Teeth", IEEE Transactions on Magnetics, Vol. 41, No. 11, pp. 4304-4308, Nov. 2005

[4] Y.G. Guo, J.G. Zhu, P.A. Watterson, and W. Wu, Development of PM Transverse Flux Motor With Soft Magnetic Composite Core, IEEE Transactions on Energy Conversion, Vol. 21, No. 2, June 2006

[5] Y. Chen and P. Pillay, "Axial-flux PM Wind Generator with a Soft Magnetic Composite Core", Conference Record of the 2005 IEEE Industry Applications Conference Annual Meeting, p. 231- 237.

[6] G.S. Liew, N. Ertugrul, W.L. Soong and J. Gayler, "Investigation of Axial Field Permanent Magnet Motor Utilising Amorphous Magnetic Material", Australasian Universities Power Engineering Conference (AUPEC) Proceedings, Vol. 2, pp. 592-597, Australia, Sep. 2005.

[7] J. Wang and D. Howe, "Influence of Soft Magnetic Materials on the Design and Performance of Tubular Permanent Magnet Machines", IEEE Transactions on Magnetics, Vol. 41, No. 10, October 2005

[8] A.G. Jack, B.C. Mecrow, P.G. Dickinson, D. Stephenson, J.S. Burdess, N. Fawcett, and J.T. Evans, "Permanent-Magnet Machines with Powdered Iron Cores and Prepressed Windings", IEEE Transactions on industry applications, Vol. 36, No. 4, July/August 2000

[9] JMAG-Studio 8.4 User's Manual Pre/Post (English version), JMAG-Studio Group, Engineering Technology Division, The Japan Research Institute, Ltd., Tokyo, Japan, 2005.

[10] JMAG-Studio 8.4 Tutorial Magnetic Field (English version), JMAG-Studio Group, Engineering Technology Division, The Japan Research Institute, Ltd., Tokyo, Japan, 2005.

[11] B.C. Mecrow, A.G. Jack and S.A. Evans, "Permanent Magnet Machines with Soft Magnetic Composite Stators", International Conference on Electrical Machines, Vol. 2/3, pp. 346-351, Istanbul, Turkey, Sep. 1998. 